\title{
Gas Sensing Mechanism of Metal Oxide Doped PANi Composites
}

\author{
Kailash R. Nemade and Sandeep A. Waghuley \\ Department of Physics, Sant Gadge Baba Amravati University, Amravati 444 602, India
}

Received: December 03, 2012 / Accepted: January 06, 2013 / Published: May 25, 2013.

\begin{abstract}
Novel hybrid gas-sensitive materials were made-up by means of metal oxide (MOX) doped organopolymers. The hybrid gas-sensitive materials were prepared by varying molar concentration of $\mathrm{Bi}_{2} \mathrm{O}_{3}$ and $\mathrm{Y}_{2} \mathrm{O}_{3} \mathrm{MOX}$ in conducting polymer PANi. The hybrid materials have tested upon exposure to LPG gas. The sensitivity of both composites materials was studied at room temperature. The gas sensing mechanism explained on the basis of chemisorbed/adsorbed oxygen. The materials were characterized by FTIR and SEM analysis.
\end{abstract}

Key words: Gas sensing, metal oxide, PANi.

\section{Nomenclature}

PANi:

$$
\text { Polyaniline }
$$

\section{Introduction}

Polymer-metal or metal oxide nanocomposite is a new class of material that combines the advantages of both organic polymer material and inorganic metal or semiconductor oxide and shows improved optical, electrical and mechanical properties for gas sensor applications. The gas sensing properties of films depend not only upon the individual components used but also on the morphology and the interfacial characteristics. The composite films that combine materials with synergetic behaviours possess unique physical, chemical, optical, mechanical, magnetic and electrical properties unavailable from that of the component materials and have attracted much attention for a wide range of device applications such as gas sensors. Recently, various nanocomposite films consisting of either metal-metal oxide, mixed metal oxides, polymers mixed with metals or metal oxides, or carbon nanotubes mixed with polymers, metals or

Corresponding author: Sandeep A. Waghuley, Ph.D., professor, research fields: sensors, conducting glasses. E-mail: sandeepwaghuley@sgbau.ac.in. metal oxides have been synthesized and investigated for their application as active materials for gas sensors. Design of the nanocomposite films for gas sensor applications needs the considerations of many factors, such as the surface area, interfacial characteristics, electrical conductivity, nanocrystallite size, surface and interfacial energy, stress and strain, etc. which depend significantly on the material selection, deposition methods and deposition process parameters. The conducting polymers have shown great promise is in sensory applications. The localized electronic states combined with the restriction on the extent of delocalization makes most of the conductive polymers behave like p-type semiconductors. As these polymers are redox-active, their conductivity can be changed by means of doping/dedoping. A great number of sensing applications are designed by exploiting nature of conducting polymers [1]. Cioffi, et al. investigated polymer films embedded with $\mathrm{Pd}$ or Au nanoparticles for detecting vapours of organic solvents [2].

The importance of environmental gas monitoring is well understood and much research has been focused on the development of suitable gas sensitive materials. Recently, there has been considerable interest in exploiting organic substances such as porphyrin, 
phthalocyanines and doped conductive polymers for this purpose. The conducting polymers are good candidates for the elaboration of chemical or electrochemical sensors. Among the conducting polymers, polyaniline (PANi) is a promising sensing material and can be synthesized by chemical, electrochemical or plasma methods, and in each case, the composition, morphology and physical properties of the resulting polymer are strongly dependent on the detailed reaction conditions [3].

In present work, two different composites were synthesised by chemical route. The $\mathrm{PANi} / \mathrm{Bi}_{2} \mathrm{O}_{3}$ and $\mathrm{PANi} / \mathrm{Y}_{2} \mathrm{O}_{3}$ composites were prepared by varying molar concentration of MOX. The prepared samples were characterized by FTIR analysis on shimadzu (model: 8400s). The morphology of powders was investigated by using JEOL-JSM (Model-6063) SEM instrument.

\section{Experiments}

AR grade (SD fine, india) chemicals were used for this work. The composites $\mathrm{PANi} / \mathrm{Bi}_{2} \mathrm{O}_{3}$ and $\mathrm{PANi}$ / $\mathrm{Y}_{2} \mathrm{O}_{3}$ were prepared by chemical route. The ammonium persulphate was used as oxidant for polymerisation of PANi. The samples of $\mathrm{Bi}_{2} \mathrm{O}_{3} / \mathrm{PANi}$ composites were prepared of $0.5 \mathrm{M}$ and $1 \mathrm{M}$ tested for LPG gas whereas $\mathrm{Y}_{2} \mathrm{O}_{3} /$ PANi composites prepared by varying molar concentration from $0.4-2 \mathrm{M}$. The thick films of prepared samples were fabricated by screen-printing method on $\mathrm{SiO}_{2}$ substrate. The silver electrodes were coated on the films for electrical contact purpose. The electrical resistance of the film was measured by using a voltage drop method.

\section{Results and Discussion}

\subsection{FTIR Analysis}

The FTIR spectra of the PANi/ $/ \mathrm{Bi}_{2} \mathrm{O}_{3}$ and PANi/ $\mathrm{Y}_{2} \mathrm{O}_{3}$ composites powder samples were recorded in the range 4,000-400 $\mathrm{cm}^{-1}$ to confirm polymerisation shown in Figs. 1 and 2, respectively. The FTIR spectrum of the PANi base shows six principal absorptions at 1,590, 1,508, 1,304, 1,210, 1,145 and $831 \mathrm{~cm}^{-1}$. The peaks at $1,590 \mathrm{~cm}^{-1}$ and $1,508 \mathrm{~cm}^{-1}$ are assigned to $\mathrm{C}-\mathrm{C}$ ring stretching vibrations. The peaks at $1,304-1,310 \mathrm{~cm}^{-1}$ correspond to $\mathrm{N}-\mathrm{H}$ bending. The bands at 1,145 and $831 \mathrm{~cm}^{-1}$ can be attributed to the in plane and out-of-plane $\mathrm{C}-\mathrm{H}$ bending modes, respectively. The corresponding peaks for the PANi salt appear at 1,560, 1,482, 1,306, 1,245.9, 1,148 and $814 \mathrm{~cm}^{-1}$, respectively. The peak at $2,390 \mathrm{~cm}^{-1}$ could be attributed as due to $\mathrm{NH}$ stretching mode and the $1,653 \mathrm{~cm}^{-1}$ bond to the NH bending vibration [4]. The several peaks from 400 to $600 \mathrm{~cm}^{-1}$ attributed to vibration of $\mathrm{Bi}-\mathrm{O}$ bonds displayed in Fig. 1, confirming the formation of $\mathrm{Bi}_{2} \mathrm{O}_{3}$ [5]. The peak observed in Fig. 2 at $415 \mathrm{~cm}^{-1}$ which may be attributed to the presence of $\mathrm{Y}-\mathrm{O}$ bond in $\mathrm{Y}_{2} \mathrm{O}_{3}[6]$.

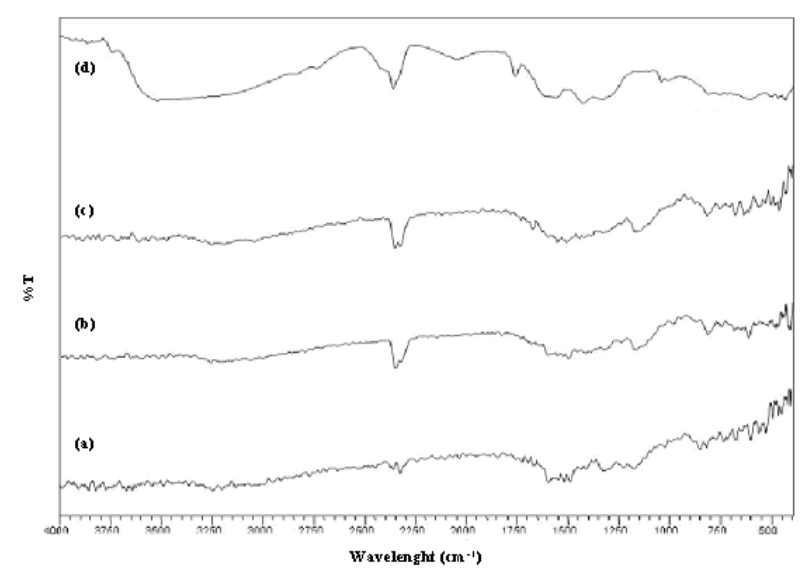

Fig. 1 FTIR spectra of (a) PANi; (b) $0.5 \mathrm{M}$; (c) $1 \mathrm{M}$ and (d) $\mathrm{Bi}_{2} \mathrm{O}_{3}$.

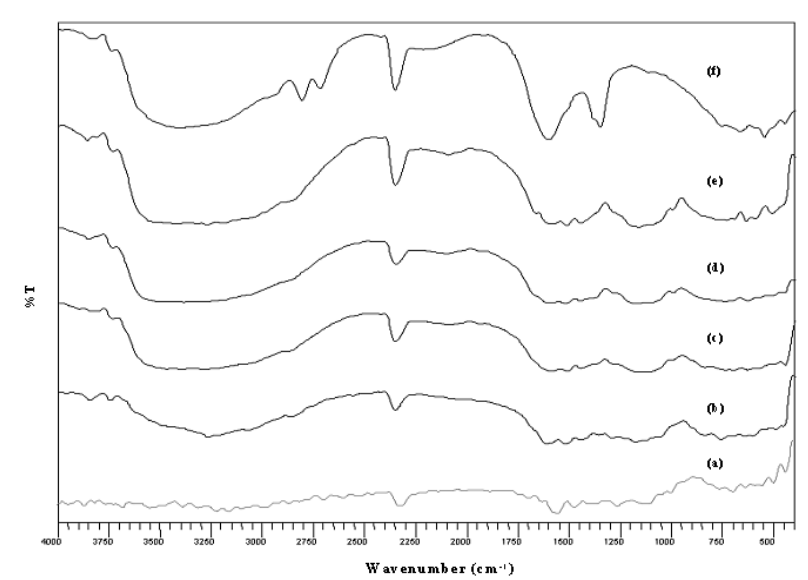

Fig. 2 FTIR spectra of (a) $\mathrm{Y}_{2} \mathrm{O}_{3}$; (b) $0.4 \mathrm{M}$; (c) $0.8 \mathrm{M}$; (d) 1.2 M; (e) 1.6 $\mathrm{M}$ and (f) $2 \mathrm{M}$. 


\subsection{SEM Analysis}

The SEM analysis examined the surface topography of prepared samples and the representative images are shown in Figs. 3 and 4. The SEM reveals an agglomerated powder with a fluffy appearance. This process yields highly agglomerated composite material with fluffy morphology, which play vital role in capturing the gas molecules. This type of morphology highly functional in gas sensing action.

\subsection{Sensing Response}

The PANi $/ \mathrm{Bi}_{2} \mathrm{O}_{3}$ composites thin films were tested towards LPG gas at room temperature. The sensor response is defined as in Eq. (1) [7].

$$
S=(R g-R a) / R a
$$

where, $R a$ is the resistance of sensor in air and $R g$ is the resistance in gas, respectively. The resistance of the films was found to be decrease with concentration of LPG. Sensing response of the films was measured for different concentration of LPG gas at room temperature Fig. 3. The gas chamber having volume 5 $\mathrm{L}$ attached to sensing system for sensors testing. Gas was introduced in chamber with the help of injection. Each injection has capacity to inlet $38 \mathrm{mg}$ LPG.

The sensing responses of $\mathrm{PANi} / \mathrm{Y}_{2} \mathrm{O}_{3}$ composites films were also tested toward LPG gas shown in Fig. 4. The sensor response is defined as Eq. (1). The resistance of the films was found to be decrease with concentration of LPG gas.

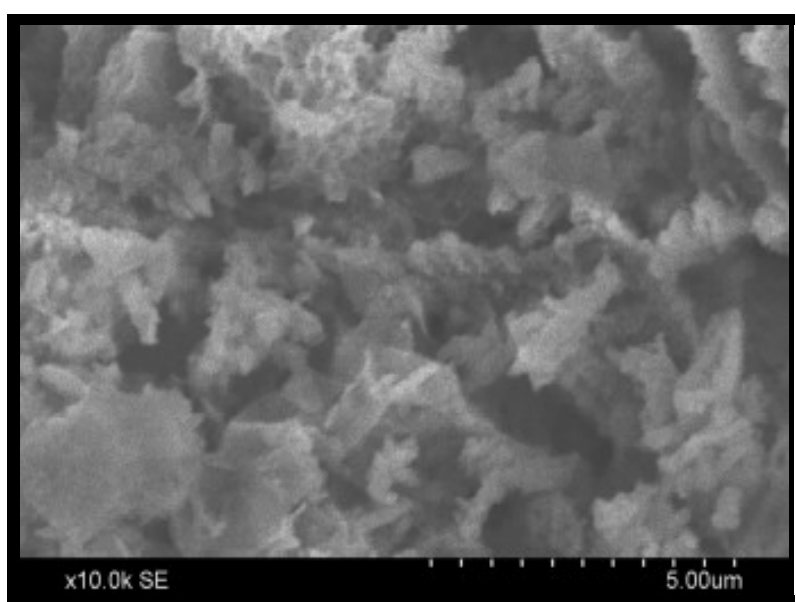

Fig. 3 SEM micrograph of $\mathrm{Bi}_{2} \mathrm{O}_{3}(0.5 \mathrm{M})$ doped PANi.

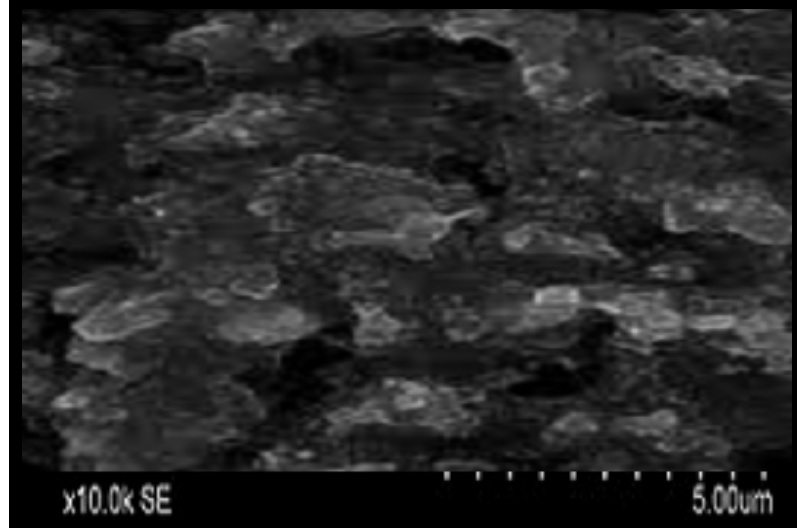

Fig. 4 SEM micrograph of $\mathrm{Y}_{2} \mathrm{O}_{3}(0.4 \mathrm{M})$ doped PANi.

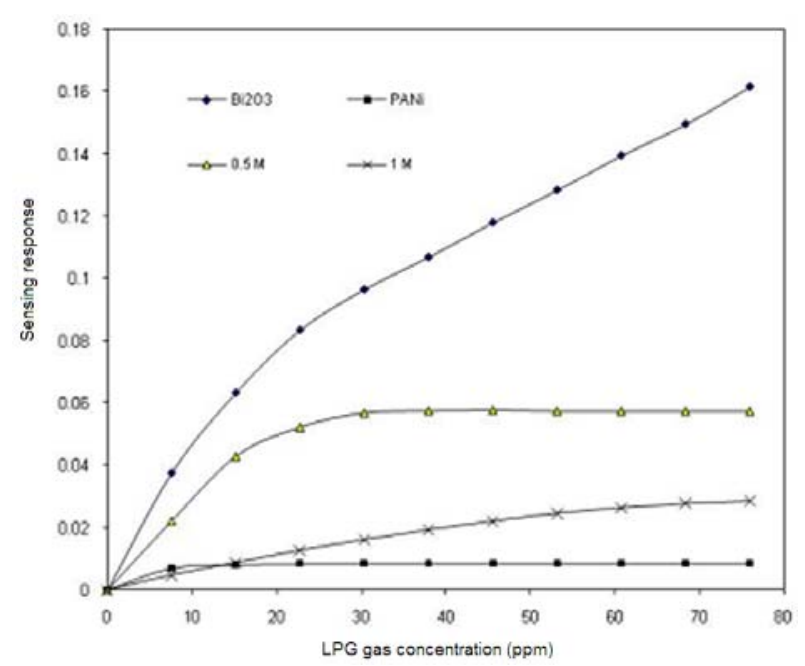

Fig. 4 Sensing response of and $\mathrm{PANi} / \mathrm{Bi}_{2} \mathrm{O}_{3}$ composites.

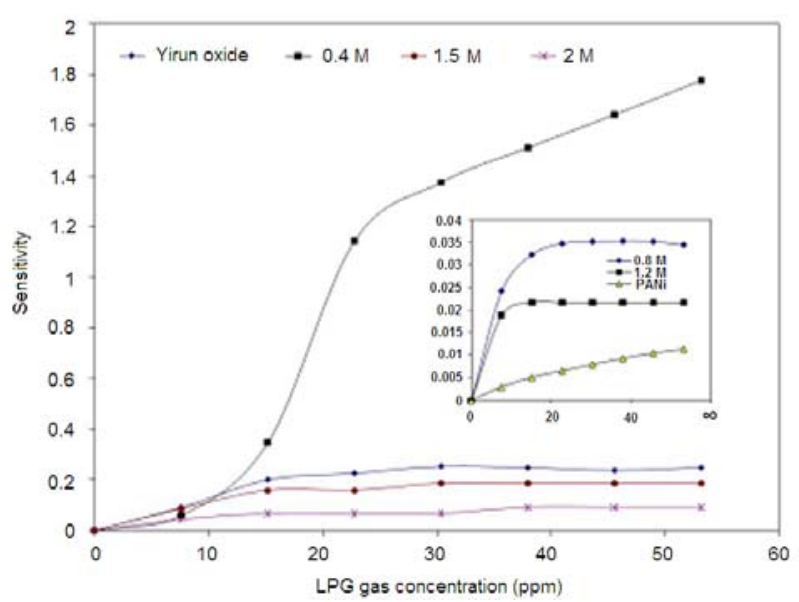

Fig. 5 Sensing response of $\mathrm{PANi} / \mathrm{Y}_{2} \mathrm{O}_{3}$ composites.

The sensing mechanisms for prepared materials were described on the basis of chemisorptions reaction. The chemisorptions reaction play different role for oxidising gas and reducing gas. The sensing mechanism for both composites explained from 
reaction on the sensor surface, resulting in a change in concentration of adsorbed oxygen. This reaction may be represented as Eq. (2) and Eq. (3) as follows

$$
\begin{aligned}
& \mathrm{O}_{2} \text { (gas) } \leftrightarrow \mathrm{O}_{2} \text { (ads) } \\
& \mathrm{O}_{2} \text { (ads) }+\mathrm{e}^{-} \leftrightarrow \mathrm{O}_{2}^{-} \text {(ads) }
\end{aligned}
$$

The free electron shown in Eq. (3) on left hand side affected by the nature of gas. The oxidising gases inject electrons from material surface, where as the reducing gases added electrons in the bulk of materials. Therefore, resistance of materials was found to be increase in presence of oxidising gas. On the other hand, resistance of materials were found to be decrease in presence of LPG gas due to its reducing nature.

\section{Conclusions}

The FTIR analysis of both composites confirmed the polymerisation of aniline monomer and composites bonding. The morphology of prepared samples studied by SEM micrograph. The surface morphology play imperative role in analysis of sensing mechanism. The sensing response found to be higher for pure $\mathrm{Bi}_{2} \mathrm{O}_{3}$ from $\mathrm{PANi} / \mathrm{Bi}_{2} \mathrm{O}_{3}$ composites at room temperature, whereas the $(0.4 \mathrm{M})$ $\mathrm{PANi} / \mathrm{Y}_{2} \mathrm{O}_{3}$ composite shows higher sensing response.

\section{Acknowledgments}

Authors are very much thankful to Head, Department of Physics Sant Gadge Baba Amravati University, Amravati for providing necessary facilities.

\section{References}

[1] S.C. Hernandez, D. Chaudhari, W. Chen, N. Myung, A. Mulchandani, Single polypyrrole nanowire ammonia gas sensor, Inter Science 19 (2007) 2125-2130.

[2] N. Cioffi, L. Torsi, I. Farella, D. Altamura, A. Valentini, N. Ditaranto, et al., Deposition and analytical characterization of luoropolymer thin films modified by palladium nanoparticles, Thin Solid Films 449 (2004) 25-33.

[3] R. Kumar, S. Singh, A.K. Misra, Development of $\mathrm{NO}_{2}$ gas sensor based on plasma polymerized nanostructure polyaniline thin film, J. Minerals and Materials Characterization \& Engineering 9 (2010) 997-1006.

[4] J. Stejskal, Polyaniline, preparation of conducting polymer, Pure Appl. Chem. 74 (2002) 857-867.

[5] F. Miyaji, T. Yoko, S. Sakka, Effect of $\mathrm{Bi}_{2} \mathrm{O}_{3}$ on physical, optical and structural studies of $\mathrm{ZnO}-\mathrm{Bi}_{2} \mathrm{O}_{3}-\mathrm{B}_{2} \mathrm{O}_{3}$ glasses, J. Non-Cryst. Solids 126 (1990) 170-175.

[6] T.K. Vishnuvardhan, V.R. Kulkarni, C. Basavaraja, S.C. Raghavendra, Synthesis, characterization and a.c. conductivity of polypyrrole $/ \mathrm{Y}_{2} \mathrm{O}_{3}$ composites, Bull. Mater. Sci. 29 (2006) 77-83.

[7] K.R. Nemade, R.S. Palspagar, K.A. Koparkar, S.S. Kosalge, G.T. Bhalerao, G.G. Muley, et al., Sensitivity and dynamic response of Zinc oxide thin films to carbon dioxide gas, Bionano Frotier (Special Issue) (2010) 133-135. 